\title{
NARRADOR SILENCIOSO? UMA LEITURA DE PEPETELA SOB A ÓPTICA DO DISCURSO DE MICHEL FOUCAULT
}

\author{
Sebastião Marques Neto ${ }^{1}$
}

Resumo: $\mathrm{O}$ objetivo deste artigo é discutir o silenciamento e o silêncio da $\mathrm{VOZ}$ narrativa em $A$ gloriosa família, do escritor angolano Pepetela - pseudônimo de Arthur Carlos Maurício Pestana dos Santos - (1999). Inspirado em Foucault, proponho-me a tratar alguns enunciados da obra, a partir do seu pensamento sobre a noção de discurso e poder, buscando a multiplicidade de acontecimentos que operam nos jogos entre o real e o ficcional; entre o fato histórico e a suas versões imersas nas práticas sociais. A idéia é articular o foco narrativo em seu duplo movimento: ora silenciado, ora em afasia, dentro de um contexto cujas relações de poder buscam ecos na escrita do filósofo francês.

Palavras-chave: Ficção, História, Representação, Discurso.

Abstract: This article aims to discuss silencing and the voicelessness of the narrative in A Gloriosa Familia, by the Angolan writer Pepetela - pseudonym of Arthur Carlos Maurício Pestana dos Santos - (1999). I intend to open up certain features of the work on the basis of Foucault's thought concerning discourse and power, seeking out the multiplicity of events operating in the play of real and fictional, historic fact and its versions immersed in social practice. The idea is to articulate the narrative focus in its double movement: sometimes silenced, sometimes aphasic, within a context whose power relations seek echoes in the French philosopher's work.

Key words: Fiction, History, Representation, Discourse.

Segundo Rolland Barthes (1980), narrativa é todo discurso que nos apresenta uma história imaginária como se fosse real, constituída por uma pluralidade de personagens cujos episódios de vida se entrelaçam num tempo e num espaço determinados.

A obra ficcional, em prosa, ao contrário da poesia que se apoderou da fantasia e da imaginação, busca ser crível e verossímil. Num romance histórico, como $A$ gloriosa família (AGF), do escritor angolano Pepetela (pseudônimo de Arthur Carlos Maurício Pestana dos Santos), o fato é olhado sob outro viés, numa polifonia de vozes oficiais e não oficiais, num entrecruzamento de discursos e versões em que quem fala, enuncia também a sua posição social dentro da sociedade angolana, do século XVII.

1 Mestrando em Família na Sociedade Contemporânea na Universidade Católica de Salvador UCSAL, Professor das Faculdades Jorge Amado (FJA-BA). Correio eletrônico: sebamneto@yahoo.com.br. 
O narrador não é o autor da obra, mas sim um papel inventado pelo autor; "é uma personagem de ficção em que o autor se metamorfoseia". Como afirma Barthes (1980), "quem fala (na narrativa) não é quem escreve (na vida) e quem escreve não é quem é".

$\mathrm{Na}$ obra AGF, o narrador-personagem é o escravo, mudo e sem nome, que apresenta a nós, leitores, a família de Baltazar Van Dum, seu dono:

Está tudo bem, está tudo bem, ia dizendo Baltazar ao bando de homens, mulheres, jovens e crianças, que o rodeava, todos seus filhos. A maior parte paridos de D. Inocência, outros feitos no quintal, cujas mães escravas já tinham atravessado o mar, exigência da esposa oficial pela lei da Igreja. Os filhos todos eram mulatos, como eu, mas havia tonalidades diferentes e uns tinham olho azul, outros verde e ainda outros castanho. Do casamento tinha ele oito filhos, do quintal o número era incerto (PEPETELA, 1999, p. 21).

O casamento seria representado pelo espaço social da casa; e a senzala, o espaço social do quintal. Os espaços sociais demarcando os papéis dos filhos na construção dessa família mestiça.

A família patriarcal, constituída por Baltazar Van Dum, holandês católico, casado com D. Inocência, "filha de um pequeno soba de Kilunda. [...] bem mais escura do que eu, seu escravo..." (PEPETELA, 1999, p. 21). Esse matrimônio seguia, em parte, o modelo trazido pelo europeu, isto é, eles foram casados perante a Igreja Católica. Ora, a família para a Igreja, no Novo Mundo, deveria ser um instrumento de luta contra o protestantismo e, consequentemente, de difusão do catolicismo. Sérgio Buarque de Holanda (1977) destaca que a família predominava como centro de todas as organizações, inclusive os escravos, no período colonial, integravam-na. O chefe da família, o pai e senhor, impunha a sua força física e o seu discurso sobre todos aqueles que lhe pertenciam. Baltazar Van Dum usava, então, os seus filhos para aumentar o seu poder e a sua lucratividade, garantindo a ampliação da mão-de-obra, obedecendo à lógica escravista da época.

$\mathrm{Na}$ relação narrador-personagem, há duas modalidades nos romances que põem em cena o foco narrativo:

$\left.1^{\circ}\right)$ Onisciência do narrador-personagem: é caracterizada pela visão totalizante do enredo e da ação narrada, bem como pela reflexão dos sentimentos das personagens; é a mediadora da ficção narrativa da realidade do autor e do leitor.

$2^{\circ}$ ) Identidade do narrador-personagem: a personagem é o centro da narração; é a partir dela e com a sua visão que percebemos os fatos relatados. Dentro dessa perspectiva, não é o narrador que nos mostra a personagem ou as personagens, e sim a personagem que se mostra a nós e nos impõe a sua visão.

O narrador mudo ou emudecido de AGF usa um mote para se posicionar explicitamente ao leitor como escravo: "O meu dono". Sabemos que seu dono é 
Baltazar Van Dum, um rico traficante de escravos, estabelecido em Luanda. Mas ele é dono de quem? Como se chama aquele que tem a voz narrativa e nos indica a hierarquia social? Sem nome, desprovido até de um mero apelido, a voz narrativa sinaliza a ausência de sua condição de protagonista dos fatos narrados. Onisciente, o narrador-personagem observa e questiona a ordenação do mundo que não lhe pertence, mas que sobre ele recaem variadas conseqüências:

O meu dono começou a andar para casa e eu lá fui atrás, era para isso que existia. [...] Se me pusessem dois pistolões à cinta ou um sabre, seria um esplêndido guarda-costas. Mas desarmado nem sei o que sou (PEPETELA, 1999, p. 14).

Questiona-se sobre a sua utilidade. Para que servia o ser possuído pelo "dono"? Emudecido ou mudo, esse escravo é um pajem, alguém que acompanha o seu dono em vários lugares, mas não entra nos espaços sociais do branco. Isto é, numa sociedade escravista, o escravo não é uma pessoa. Vale como objeto, mercadoria, animal de carga.

O major e o meu dono saltaram para cima dos cavalos, tive de correr para acompanhar o passo. Chegaram ao colégio, desmontaram, entraram sem cumprimentar o sentinela, nem olharam para mim. Quer dizer, era escusado me ter cansado a correr para ficar ali à porta, sem ter merecido ao menos um olhar. Como se eu não existisse. Mas existiria mesmo? Só pelo orgulho do meu dono, que fazia questão em me apresentar a novos conhecimentos, um escravo que a Jinga me deu (PEPETELA, 1999, p. 124).

Vale ressaltar: quem existe? Como ele era apresentado? Quem Jinga deu a quem? O escravo foi obtido por Baltazar através de uma trapaça sobre a rainha africana - que se tornou famosa pela violência de seu temperamento e pelo combate ao colonialismo. Ora, a origem daquele escravo pessoal demonstrava a ostentação ameaçadora e a vaidade de Baltazar:

Contava porque era mais forte do que ele [...]. Mas tinha, ao mesmo tempo, perfeita noção de que o melhor seria deixar esquecer o assunto [...] não seria nada bom para a saúde dele, se Jinga lembrasse que ele havia afirmado vir do lado holandês quando afinal vivia na Luanda portuguesa que ela odiava. Só que era mais forte do que ele (PEPETELA, 1999, p. 125).

Tornado fetiche pelo "seu dono", o escravo valioso como mercadoria desejada é anulado, simultaneamente, como pessoa. A sua captura se deu distante, em território inimigo, em localidades as mais distanciadas quanto possível da casa, espaço afetivo da família Van Dum. Obedecia-se a uma estratégia de rompimento dos laços sociais de origem do indivíduo aprisionado, que repercutiriam na despersonalização que vai convertê-lo em mercadoria: "A distância geográfica preparava a distância social quase absoluta, apesar de todas as aparências, que separaria o es- 
cravo do senhor, e o imobilizaria em seu estado irreversível de estranho" (MEILLASSOUX, 1995, p 55).

Seguindo as idéias de Foucault (1992) em "A Vida dos Homens Infames", cujos documentos pesquisados remontam aos séculos XVII e XVIII, na França, são analisadas cartas dirigidas ao rei pedindo a prisão de desertores, vagabundos, soldados, monges e homens e mulheres escandalosas. Para o autor, essas pessoas que sofreram o gesto aprisionador excludente; gesto que encerra significações políticas, sociais, religiosas, econômicas e morais, viveriam em esquecimento histórico, se não houvesse tais documentos.

Esse privilégio dominou todo o Renascimento e, sem dúvida, foi um dos grandes acontecimentos da cultura ocidental. A imprensa, a chegada à Europa dos manuscritos orientais, o aparecimento de uma literatura que não era mais feita pela voz ou pela representação nem comandada por elas, a primazia dada à interpretação dos textos religiosos sobre a tradição e o magistério da igreja - tudo isso testemunha, sem que se possam apartar os efeitos e as causas, o lugar fundamental assumido, no Ocidente, pela Escrita (FOUCAULT, 1999, p. 53).

O escravo-narrador enuncia uma transgressiva biografia do seu dono, Baltazar Van Dum, próspero traficante de origem flamenga cuja habilidade para lidar com os negócios fizera dele uma figura central nos jogos de poder que disputavam o controle da máquina escravista. Gerenciando uma rede de afetos e interesses que se multiplicavam para além da sua grande família de filhos mulatos, estendendo-se a influentes amizades entre holandeses, portugueses e congoleses, Baltazar apresenta-se, enfim, como uma personagem emblemática para observarmos a construção de uma identidade híbrida produzida pela experiência colonial.

A problemática da voz narrativa de um escravo sobre o seu dono e os recursos ficcionais utilizados dão testemunho da relação senhor - escravo numa visão dupla. Como a liga de uma moeda, o explorador está ligado ao explorado e viceversa.

Afinal o meu dono fazia coisas nas minhas costas, escondia-me dados importantes? [...] Abri mais os ouvidos e a partir dessa noite dormi ainda menos. A imaginação trabalhava para me entreter nas horas de espera. Grande sonso, o meu dono, não era mesmo feio trair o seu escravo de estimação? Nunca lhe pedi nada, nem mesmo a liberdade, não perco tempo nem saliva a pedir o impossível. Não merecia ao menos um pouco de transparência nos seus gestos, eu que me alimento praticamente do que vejo e oiço? Não é só curiosidade vã, eu tenho sentido da história e da necessidade de a alimentar, embora os padres e outros europeus digam que não temos nem sabemos o que é História. Sou muito diferente do governador Pedro César de Menezes, que deixou perderem-se todos os documentos de Luanda [...]. [...] Depois somos nós que não temos sentido da história, só porque não sabemos escrever. Eu, pelo menos, sinto grande responsabilidade 
em ver e ouvir tudo para um dia poder contar, correndo as gerações, da mesma maneira que aprendi com outros o que antes sucedeu. Por isso o meu dono não tinha o direito de tentar me esconder tão magnos acontecimentos que passam na sua cabeça, mesmo se um pouco loucos (PEPETELA, 1999, p. 118).

De acordo com Foucault (1999), "Saber consiste, pois, em referir a linguagem à linguagem. Em restituir a grande planície uniforme das palavras e das coisas. Em fazer tudo falar. Isto é, em fazer nascer, por sobre todas as marcas, o discurso segundo comentário". A identidade silenciada é, aos poucos, recuperada pelo escravo sem voz, mas que pensa e aprende o ritmo dos estrangeiros; aprende a ouvir as línguas do dominador, seja o holandês, português ou francês.

Posso dizer que sou um filho do Kuanza, pois nasci no meio dele [...]. Olhar o Kuanza sempre me deu um nó de saudade na garganta e o dia de hoje tem sido particularmente sentido, com o regresso ao berço, o que embacia os olhos e endurece os ouvidos, por isso decidi ali, tenho de ser imparcial e objectivo, o meu passado não interessa, apenas tenho de relatar os factos tal como os viveu o meu dono e a sua gloriosa descendência, para isso fui criado (PEPETELA, 1999, p. 259).

Observamos que o narrador-personagem começa a descobrir a sua utilidade: "para isso fui criado", ou seja, a sua história, por menor que seja, compõe o mosaico das vidas e dos corpos em que se inscreveram a dominação européia na África, em particular em Angola.

Um narrador mudo demonstra como o apagamento da língua falada pelo escravo, negro e oprimido pelo sistema escravocrata da época, envolve a própria afasia da língua. Segundo Maurizio Gnerre (1985), a língua é "o arame farpado mais poderoso para bloquear o acesso ao poder". Entretanto, através da ficção, o narrador-personagem opera mudanças significativas para a sua sobrevivência.

Um escravo não tem direitos, não tem nenhuma liberdade. Apenas uma coisa lhe não podem amarrar: a imaginação. Sirvo-me sempre dela para completar relatos que me são sonegados, tapando os vazios. [...] eu é que estou a saltar de um tempo para o outro, pois é a única liberdade que tenho saltar no tempo com a imaginação e assim tenho ido nesta caminhada para casa, saltitando da amizade do major para os negócios e o sofrimento que se passou e passa nesta terra (PEPETELA, 1999, p. 16).

Muito próximo dos procedimentos ficcionais do narrador-personagem em Dom Casmurro, (1899) de Machado de Assis, que afirmava - "A verossilhança... é muita vez toda a verdade".

Concebe-se a ficção como o espaço de produção de sentidos, reveladora dos valores significativos e dissimulados, muitas vezes, nos discursos oficiais sobre a missão colonizadora e sobre a imposição ao povo autóctone dos sistemas organi- 
zados e simbólicos dos europeus, a saber, a língua e a religião que juntas, através da catequização, formaram uma única força a serviço da Metrópole. "Na idade moderna, a literatura é o que compensa (e não o que confirma) o funcionamento significativo da linguagem" (FOUCAULT, 1999, p. 60).

A obra de Pepetela torna-se um conjunto de "acontecimentos discursivos" (FOUCAULT, 1986), uma vez que interpreta, através da escrita do presente, um outro conjunto de "acontecimentos discursivos" cujas singularidades estão em um outro momento diverso e passado).

O sentido histórico comporta três usos que se opõem, palavra por palavra, às três modalidades platônicas da história. Um é o uso paródico e destruidor da realidade que se opõe ao tema da história-reminiscência, reconhecimento; outro é o uso dissociativo e destruidor da identidade que se opõe à história-continuidade ou tradição; o terceiro é o uso sacrifical e destruidor da verdade que se opõe à história-conhecimento (FOUCAULT, 1999, p. 33).

Assim como o discurso instaura o poder, o silenciamento ou a mudez do narrador-personagem que pouco se comunica com a família de "seu dono", ou seja, que não realiza trocas através da oralidade, estabelece uma ruptura ao desvelar as malhas do poder para nós, leitores que, aos poucos, vamos nos identificando com aquele que nos conta a história gloriosa. Mesmo sem ser o protagonista, é de sua mudez que emerge o discurso pertinente e fundamental para que entendamos o discurso violento e a violência física, que se inscreve em corpos negros, e a verbal com seu aspecto unívoco e silenciador dos outros discursos.

Aos não-europeus não era dada a possibilidade de compor em auto-imagens, de falar a respeito de si mesmo e de colocarem-se como sujeitos dos discursos de representação. Seus perfis e imagens eram construídos pelos europeus que procuravam fixá-los e introjetá-los na mente dos representados (SOUZA, 2005, p. $52)$.

Publicado em 1999, no Brasil, o romance relata os périplos e as desventuras de um africano que, naqueles tempos da expansão colonial portuguesa, em meio às guerras religiosas e comerciais do século XVII, vivencia a experiência de tornar-se escravizado. A obra inscreve-se na fronteira entre os registros historiográficos e literários, utilizando recursos de atualização narrativa e de reversão de valores que são emblemáticos dos estilos de intervenção pós-colonial. Com foco narrativo em primeira pessoa, a reconstrução ficcional da voz do escravo, traz à ribalta o recalcado, uma vez que a estrutura do discurso busca investigar o latente. Ao colocar a mudez do narrador, projeta-se um olhar que rompe com o legado cultural de neutralização e dá legitimidade à fala de um sujeito-narrador violentado, no plano físico e psicológico pela lógica da escravidão. 
A partir de 1980, a literatura africana de língua portuguesa passa a mobilizar reflexões e interesses sobre os seus modos de ver o mundo, principalmente a visão pós-colonialista da África. A literatura africana desse período engloba o memorialismo, o sentimento nacional, a busca identitária e a sua relação com o Brasil. Porém, em todos esses aspectos, os escritores estabelecem jogos entre a literatura e a história, buscando a fundação da sua própria história, numa rede intricada de invasões, dominações, resistências e independências.

Ora, a literatura capta as variadas formas de ler e escrever os movimentos contraditórios que percorrem a vida mínima e cotidiana do povo africano. As trocas culturais com os europeus se deram em mão-dupla, mesmo ignoradas ou negadas pelo etnocentrismo. Com o Brasil, impossível negá-las ou torná-las menores ou desimportantes para a nossa formação cultural.

As interconexões (das relações de poder) delineiam condições gerais de dominação e essa dominação é organizada em uma forma mais ou menos coerente e unitária que, dispersos, heteromorfos, localizados procedimentos de poder são adaptados, reforçados e transformados por numerosos fenômenos de inércia, deslocamento e resistência (FOUCAULT, 1980, p. 144).

$\mathrm{Na}$ literatura pós-colonial, a identidade representa um questionamento da imagem - um escravo, fosse mudo ou não, não poderia ser o narrador da história da gloriosa família de um holandês vencedor no Novo Mundo, principalmente aos olhos e vozes eurocêntricos. Entretanto, a cisão de um sujeito constituído por outro constituinte em seu lugar histórico de enunciação rompe com status quo da narrativa tradicional, aquela em que o narrador-personagem deveria explicitar como sabe e por que sabe dos fatos narrativos. Tal mudança obriga-nos a nós, leitores, a uma nova forma de leitura, crítica e tateante. Nós, leitores, ficamos atrás do escravo-narrador, pois é através de suas observações e contra-discursos que apreendemos as leis de ordenação do mundo, africano colonialista.

A partir do século XIX, a literatura repõe à luz a linguagem no seu ser: não, porém, tal como ela aparecia ainda no final do Renascimento. Por que agora não há mais aquela palavra primeira, absolutamente inicial, pela qual se achava fundado e limitado o movimento infinito do discurso; doravante a linguagem vai crescer sem começo, sem termo e sem promessa. É o percurso desse espaço vão e fundamental que traça dia a dia, o texto da literatura (FOUCAULT, 19999, p. 61).

Por ninguém o ver, sem nome ou utilidade maior do que seguir Baltazar Van Dun: "ele foi muito claro no princípio da nossa relação, andas sempre atrás de mim, [...] não foi preciso mais nada, nunca ouvi um berro" (PEPETELA, 1999, p. 188), a voz narrativa rompe a neutralidade inerente a sua época e condição de escravo, burlando o estabelecido e investigando a rotina da casa e do quintal. Ao se constituir na voz narrativa onisciente, embora emudecido pelo colonizador, o es- 
cravo não se mantém inerte ou passivo frente às representações do que lhe é imposto como ordem; dominando a cultura do colonizador ou colonizadores, através de comportamento especioso, ele transita e transgride a ordem do discurso dominado.

Um escravo não tem direitos, não tem nenhuma liberdade. Apenas uma coisa lhe não podem amarrar: a imaginação. Sirvo-me sempre dela para completar relatos que me são sonegados, tapando os vazios (PEPETELA, 1999, p. 14).

Ao seguir aquele que governa a sua vida, o narrador-personagem, de $A G F$, tece o mapa pormenorizado do mundo colonialista luso-holandês na África - com conseqüências para o Brasil. A sua invisibilidade, a sua não nomeação, a sua subalternidade vai marcando, no texto, paradoxalmente a sua transgressão ficcional.

[...] eu é que estou a saltar de um tempo para o outro, pois é a única liberdade que tenho saltar no tempo com a imaginação e assim tenho ido nesta caminhada para casa, saltitando da amizade do major para os negócios e o sofrimento que se passou e passa nesta terra (PEPETELA, 1999, p. 16).

Preenchendo os vazios, convertendo em disfarce o seu silêncio, o escravo encontra uma utilidade, capaz de situá-lo no jogo de poder e de linguagem em que se configuram as identidades coloniais. Dessa forma, Baltazar Van Dum, personagem nomeado e histórico, tem a sua fala ressignificada ou apropriada pela onipresença ambígua de seu escravo.

O próprio representante do rei do Kongo tinha de reconhecer a determinação de Jinga, o que muito me envaidecia. Foi esse sentimento de orgulho pelo meu rei que nos acompanhou no regresso à cidade (PEPETELA, 1999, p. 333).

Irônico, o escravo, narrador-personagem, descreve a hierarquia do seu dono, dando visibilidade a sua forma de narrar: "Baltazar era muito pouco observador, o que ele tinha a menos tinha eu a mais, para compensar tudo o que ele tinha e eu nada" (PEPETELA, 1999, p. 55).

O escravo domina o gestual de seu dono, faz um arremedo do fato heróico e oficial, decompõe, através da imitação, e transgride o papel de dominado.

Baltazar Van Dum sorriu agradado. Gostava de discutir política com os filhos, era uma forma de os educar, mostrando que o mundo não era só aquela terra vermelha. E ele sempre teve o vício da política, pelo menos de a comentar. [...] Eu encostei melhor na parede da varanda, para que a resposta do meu dono, que eu conbecia por antecipação, me chegasse nítida através da janela. Gostava de notar a diferença nas palavras, à medida que o tempo passava sobre o mesmo relato (PEPETELA, 1999, p. 25).

$\mathrm{Na}$ biografia não autorizada de Baltazar, inscreve-se uma outra narrativa que produz a visibilidade das rotinas hipócritas e violentas, de sujeição e de resistência, 
que disciplinava as sociedades constituídas sob a dominação patriarcal e mercantil. O narrador-personagem, ao produzir a história dessa gloriosa família, torna-se sujeito cuja experiência, marcada na pele, se estende na memória ficcional. A casa e o quintal, espaços de poder e de trocas simbólicas e materiais entre os membros da família, representam a micro-estrutura doméstica das ambivalências e impasses do desejo colonial que se relacionam com uma macro-estrutura de dimensão política, em que os processos de negociação obedecem à lógica do colonialismo do século XVII.

Discurso, para Foucault (1999), designa o ato de pensar como uma prática social. Ora, onde há o poder para a sujeição do outro, há também a resistência de outro contra este que lhe impõe a ordem do seu discurso. Durante muito tempo, foram negadas ao escravo formas organizadas de luta ou de resistência. O escravo era descrito como um ser passivo, acomodado a sua condição servil e a ser, por natureza, um subalterno. Claro que isso interessava a uma visão etnocêntrica em que a cultura européia hierarquizava de forma hegemônica as outras culturas, colocando a africana por baixo.

A literatura africana do pós-colonialismo é um exemplo da resistência negra. Nomes como Agostinho Neto, José Craveirinha e Pepetela - pseudônimo de Arthur Carlos Maurício Pestana dos Santos - despontam no cenário da língua portuguesa. Estão unidos não só pela língua, mas também pela participação política em suas sociedades.

A gloriosa família (1999), de Pepetela, inscreve-se nesta rota de buscar os indícios da fundação do povo angolano cuja cultura, há muito, tornou-se híbrida pela convivência forçada com holandeses e portugueses que, durante muitos séculos, ergueram as suas espadas e vozes sobre esse espaço, no litoral da África.

Em A gloriosa familia: o tempo dos flamengos traz o século XVII, precisamente os sete anos (1642 a1648) em que os holandeses foram buscar, em Luanda, escravos, por isso um subtítulo que nos situa temporal e economicamente numa Angola invadida por traficantes portugueses e holandeses, cujas negociações se davam com reis e rainhas da terra, descrevendo uma sociedade conturbada escravagista da África colonial.

O escravo, no romance AGF, responde à engrenagem escravocrata européia com diversas metamorfoses, tornando-se, inesperadamente, no condutor da história; no sujeito-narrador; aquele que possui o poder prismático de nos revelar o que estaria escondido do humano olhar e do discurso do poder; quebra aquela abordagem única de que o escravo era um objeto submisso ao seu proprietário; rompe com aquela relação de mão única entre o escravo, coisificado, e o senhor, grande pensador econômico, do mundo colonial.

O escravo mudo ou emudecido, narrador-personagem de AGF, emerge, assim, na micro-estrutura familiar do holandês Baltazar Van Dum, como exemplo 
foucaultiano de que o poder não existe por si, porém nas práticas sociais, e a resistência ao poder se realiza dentro da rede social, numa multiplicidade de forças. $\mathrm{O}$ escravo não é dono de seu corpo, cujas ações são adestradas pelo "dono", a sua sexualidade, o seu sono, o seu prazer não existem para Baltazar. O escravo é apenas uma mercadoria ou objeto, por isso o anonimato, como a não o individualizar. Negando, dessa forma, a ele o poder e os saber que se implicam concomitantemente.

Evidentemente que os escravos deram falta logo que foram arrumar o quarto. Mas como ninguém pergunta nada aos escravos, eles também não se sentiram na obrigação de avisar, o que me parece justo. Como disse o mais velho deles, mais tarde na cozinha, em maka de brancos só burro se mete (PEPETELA, 1999, p. 144).

A ficção narrativa de AGF consegue denunciar os gestos de passado, a violência do tráfico negreiro, e a escravidão em solo africano praticada pelos europeus. Recupera, também, o testemunho daquele que sofreu o hibridismo cultural e dele se aproveitou como forma estratégica de sobrevivência e resistência. Através de sua narrativa, percebemos as brechas do sistema colonial e os seus desdobramentos no olhar crítico sobre "seu dono", metonímia da hierarquia colonial e de suas práticas de poder.

E essa dependência da língua relativamente ao saber libera todo um campo histórico que não existira nas épocas precedentes. Algo assim como uma história do conhecimento torna-se possível. É que, se a língua é uma ciência espontânea, obscura a si mesma e inábil - em contrapartida é aperfeiçoada pelos conhecimentos que não se podem depositar em suas palavras sem nelas deixar seu vestígio e como que o lugar vazio de seu conteúdo. As línguas, saber imperfeito, são a memória fiel do seu aperfeiçoamento. Induzem em erro, mas registram o que se aprendeu. Em sua ordem desordenada, fazem nascer falsas idéias; mas as idéias verdadeiras nelas depositam a marca indelével de uma ordem que o acaso somente não poderia dispor (FOUCAULT, 1999, p. 121).

Por fim, vale ressaltar ainda que em AGF, Pepetela dialoga com António Cadornega, um dos primeiros historiadores angolanos, um dos primeiros sujeitos a ser protagonista da história africana, através de fragmentos em forma de epígrafe abrindo os capítulos para recriar o tempo histórico. A História geral das guerras angolanas, de António Cadornega, garante ao leitor que o protagonista Baltazar Van Dum foi um dos homens mais influentes na Angola daquele período. Para homenageá-lo mais uma vez, Pepetela o coloca na obra como personagem secundário, criando, assim, mais uma vez a polifonia narrativa a utilizar outras vozes em seu relato. 


\section{REFERÊNCIAS}

BARTHES, Roland. Novos ensaios críticos / O grau zero da escritura. São Paulo: Cultrix, 1980.

FOUCAULT, Michel. Microfísica do poder. 4. ed. Rio de Janeiro: Graal, 1984.

FOUCAULT, Michel. As palavras e as coisas: uma arqueologia das ciências humanas. São Paulo: Martins Fontes, 1999.

FOUCAULT, Michel. A ordem do discurso. 8. ed. São Paulo: Loyola, 2002.

FOUCAULT, Michel. A vida dos homens infames. In: Id. O que é um autor? Lisboa: Veja, 1992.

GNERRE, Maurizzio. Linguagem, escrita e poder. São Paulo: Martins Fontes, 1985.

HOLANDA, Sergio Buarque de. Visão do paraíso. São Paulo: Nacional (Brasiliana), 1977.

MACHADO DE ASSIS, Joaquim Maria. Dom Casmurro. In: Id. Obra completa. Rio de Janeiro: José Aguillar, 1959.

MEILLASSOUX, Claude. Antropologia da escravidão: o ventre de ferro e dinheiro. Rio de Janeiro: Jorge Zahar, 1995.

PEPETELA. [Pseudônimo de Arthur Carlos Maurício Pestana dos Santos]. A gloriosa familia: o tempo dos flamengos. Rio de Janeiro: Nova Fronteira, 1999.

SOUZA, Florentina da Silva. Afro-descendência em Cadernos Negros e Jornal do MNU. Belo Horizonte: Autêntica, 2005. 
